\title{
PERANCANGAN BUKU ILUSTRASI PENGENALAN SENI JARANAN KEDIRI UNTUK ANAK USIA 7 - 11 TAHUN
}

\author{
Faisal Ilham Perdana ${ }^{1)}$, Masnuna ${ }^{2),}$ Diana Aqidatun Nisa ${ }^{3)}$ \\ ${ }^{1,2,3}$ Progdi Desain Komunikasi Visual, Fakultas Arsitektur dan Desain \\ Universitas Pembangunan Nasional Veteran Jawa Timur \\ E-mail: faisalilham1905@gmail.com¹, masnuna.dkv@upnjatim.ac.id², diananisa.dkv@upnjatim.ac.id²
}

\begin{abstract}
Indonesia is a country that has many local arts, one of which is the Jaranan Art, which is a dance performed by several people on imitation horses made of woven bamboo, Jaranan itself has several different versions in each region, one of which is Jaranan Kediri, Jaranan art is still preserved in several local areas in Kediri, but only a few groups are still maintaining the art of Jaranan Kediri, the younger generation who are expected to continue the art of Jaranan has started to fade (Prakasa et al., 2016). As Iptu Rudi Darmawan said, the existing ancestral cultural arts (Jaranan) are no longer preserved (Nugroho, 2021), apart from the results of observations and interviews it was found that there is still a lack of information media that provides about the art of Jaranan Kediri, so that children cannot understand what Jaranan Kediri is, therefore this paper discusses how to design a media illustration book that contains information about Jaranan Kediri for children aged 7-11 years. This paper uses a two-stage research method, namely the preparation stage and the creation stage, at the preparation stage there are several stages including data collection, $5 \mathrm{~W}+1 \mathrm{H}$ analysis, synthesis and determination of design objects, while the creation stage consists of pre-production, production and post-production. With the information media of this illustration book, it is hoped that it can make children able to understand the art of Jaranan Kediri more deeply, so that children are aware of the importance of learning traditional arts to maintain its sustainability.
\end{abstract}

Keywords: illustration book, art, Jaranan, Kediri

\section{PENDAHULUAN}

Kesenian merupakan salah satu hal dari kebudayaan yang memiliki nilai keunikan dan keindahan tersendiri. Indonesia merupakan negara dengan banyak warisan kesenian, salah satunya adalah kesenian tari Jaranan atau biasa disebut kuda lumping. Dikutip dari negerikuindonesia.com, Kesenian Jaranan merupakan kesenian tari yang dilakukan oleh beberapa orang dengan menaiki kuda tiruan yang terbuat dari bambu anyaman (NegerikuIndonesia.com, 2015).

Kesenian Jaranan merupakan kesenian budaya yang didalamnya gerakan tarian yang dilakukan oleh beberapa pemain seperti pentulan, celengan, barongan, dan pemain jaranan sendiri, selain itu terdapat pula alat musik yang mengiringi pentas jaranan, seperti gamelan, kenong, kendang, dan gong. Jaranan terkenal dengan adegan kesurupannya, sampai melakukan hal-hal di luar nalar seperti memakan pecahan kaca, berjalan di atas api, dan beberapa aksi berbahaya lainnya. Pada sebagian masyarakat, jaranan mempunyai persepsi yang lain, yaitu para pelaku jaranan adalah penyembah roh kuda, tetapi sebenarnya simbol kuda sendiri adalah untuk menunjukkan semangat dalam memotivasi hidup (Winarsih, 2010).

Kesenian jaranan adalah salah salah satu seni tradisional yang masih ada sampai sekarang, salah satunya di daerah Kediri. Di sisi 
lain pengetahuan anak muda tentang Jaranan masih kurang, terbukti dengan observasi dan wawancara yang dilakukan perancang di beberapa daerah di kota Kediri menunjukkan media informasi terkait dengan kesenian jaranan masih sedikit, dan hal tersebut dapat menimbulkan punahnya kesenian Jaranan di Kediri Jawa Timur. Hal ini berpotensi menimbulkan kurangnya minat generasi penerus terhadap jaranan Kediri. Seperti yang dikutip dari di salah satu media berita online Jawa Pos Radar Kediri, seorang polisi, Iptu Rudi Darmawan mengatakan, Seni budaya leluhur yang ada itu kini (Jaranan) sudah tidak dilestarikan lagi. (Nugroho, 2021)

Maka dari itu diperlukan media yang menarik dan diharapkan mampu meningkatkan kepedulian anak dalam kesenian. Target audience yang dituju adalah anak umur 7 - 11 tahun. Pemilihan target audience ini dikarenakan dalam usia tersebut anak sudah dapat memahami informasi yang ditangkap dengan mudah, dan dapat langsung mempraktekkan apa yang mereka pelajari dari apa yang mereka pahami. Anak pada usia 7 - 11 tahun memasuki tahap operasional konkrit, pada tahap ini anak sudah cukup matang untuk menggunakan pemikiran logika atau operasi, tetapi hanya untuk objek fisik yang ada saat ini (Ibda, 2015). Oleh karena itu media buku ilustrasi cocok untuk memperkenalkan dan melestarikan kesenian jaranan Kediri.

Menurut Putra dan Lakoro, ilustrasi pada sebuah buku bertujuan untuk menerangkan suatu cerita agar terlihat lebih menarik dan dapat membantu pemahaman pembaca buku dengan bantuan visual yang sesuai dengan isinya (Putra \& Lakoro, 2012). Dengan memperkenalkan anak dengan buku ilustrasi dapat mempermudah dalam memahami hal yang dipelajari di dalam buku ilustrasi tersebut. "Otak manusia itu lebih suka dengan segala sesuatu yang bergambar dan berwarna. Karena gambar bisa memiliki sejuta arti sedangkan warna akan membuat segala sesuatu menjadi lebih hidup," ujar Bobby Hartanto, MPsi dalam acara konferensi Smart Parents (detik health, 2020).

\section{METODE PERANCANGAN}

Metode penelitian yang digunakan dalam perancangan ini menggunakan dua tahap, yaitu tahap persiapan dan tahap penciptaan. Tahap persiapan meliputi pengumpulan data, analisa $5 \mathrm{~W}+1 \mathrm{H}$, sintesa, dan penentuan objek perancangan. Kemudian tahap penciptaan meliputi pra produksi, produksi, dan pasca produksi. (Pradana \& Masnuna, 2021)

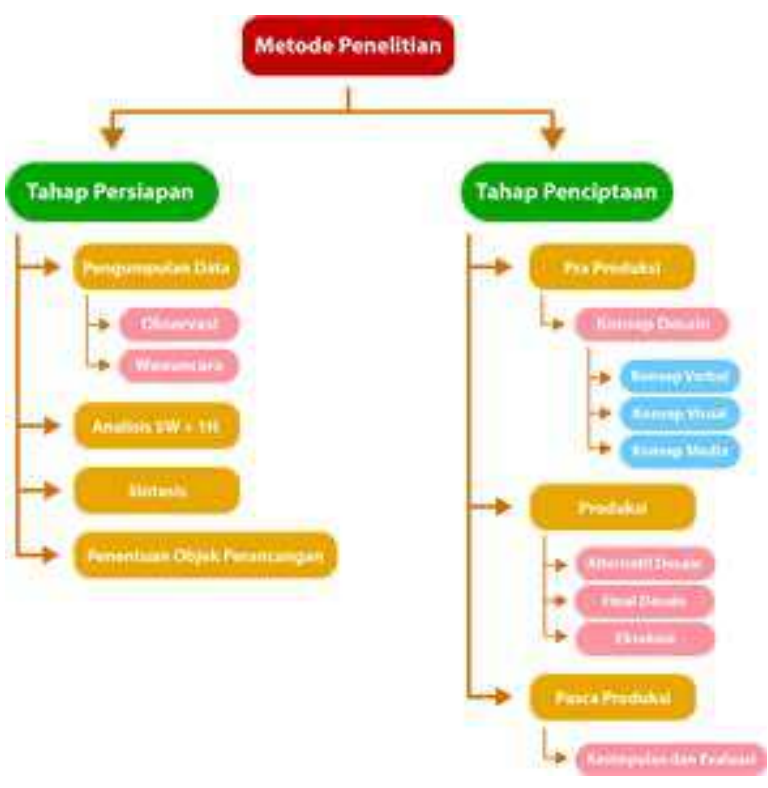

Gambar 1 Bagan Metode Penelitian Sumber: Data pribadi, 2021 


\section{Tahap Persiapan}

\section{Pengumpulan Data}

Data menjadi salah satu bagian penting dalam penelitian, dalam pengumpulan data terdapat dua metode yaitu:

\section{a. Observasi}

Observasi merupakan pengumpulan data yang dilakukan dengan mengamati dan mencatat tentang objek yang diteliti secara sistematik (Narbuko \& Achmadi, 2010). Observasi dilakukan dengan mengamati langsung konsumen, tentang jenis buku apa yang mereka sukai dalam mempelajari sesuatu, dan minat rata - rata tertuju pada buku ilustrasi, dan beberapa karya yang memiliki hubungan dengan perancangan yang akan dibuat.

b. Wawancara

Wawancara merupakan suatu percakapan yang dilakukan dua orang atau lebih yang berhadapan secara fisik dengan masalah tertentu dan merupakan proses tanya jawab secara lisan (Gunawan, 2013). Tahap ini dilakukan untuk menggali data primer mengenai buku ilustrasi untuk anak dan penjelasan kesenian Jaranan, terutama Jaranan Kediri. Wawancara ini dilakukan ke beberapa pemain jaranan, dan pakar kesenian daerah.

\section{Analisis Data 5W+1H}

Analisa data merupakan proses pengolahan data yang didapat untuk kemudian menjadi kesimpulan sederhana sehingga dapat menjawab suatu permasalahan dan fenomena yang ada (Pradana \& Masnuna, 2021). Teknik analisa data yang digunakan dalam penelitian ini adalah $5 \mathrm{~W}+1 \mathrm{H}$ (What, Why, Where, Who, When, dan How), yang bertujuan untuk menganalisa data yang telah dikumpulkan dan dapat memberikan kemudahan dalam menemukan solusi dari permasalahan yang diangkat.

\section{Sintesis}

Sintesis adalah paduan dari berbagai hal atau pengertian sehingga membentuk suatu kesatuan yang selaras (Pramitasari, 2020). Sintesis dapat berupa keyword. Sintesis juga dapat digunakan dalam membuat konsep desain sebagai acuan dalam merancang media yang akan dibuat (Pradana \& Masnuna, 2021)

\section{Objek Perancangan}

Perancangan ini menggunakan buku ilustrasi untuk anak usia 7 - 11 tahun, dan membahas pengertian jaranan Kediri, sejarah jaranan Kediri, alat musik yang digunakan dalam pentas jaranan Kediri, hingga proses pentas jaranan Kediri dari awal sampai akhir. Perancangan buku ilustrasi kesenian Jaranan Kediri terletak pada pemilihan gaya bahasa yang sederhana dan ringan mudah dipahami oleh anak usia 7-11 tahun. Tipografi yang digunakan dalam buku ilustrasi juga tidak kaku, dan lebih menyesuaikan style untuk anak. Selain itu juga mempunyai tingkat readibility dan legibility yang memadai agar mudah dipahami anak.

Target audience yang dituju dalam perancangan ini meliputi; 1) Demografis yaitu laki - laki dan perempuan dengan usia $7-11$ tahun, 2)psikografis yaitu tertarik dengan tari, suka membaca buku, mempunyai sifat yang aktif dan semangat, 3) Geografis yaitu audience yang bertempat tinggal di daerah perkotaan di wilayah Kediri. 


\section{Tahap Penciptaan}

\section{Pra Produksi}

Perancangan tahap pra produksi berguna untuk menyusun beberapa konsep desain yang diantaranya adalah, konsep verbal, konsep visual dan konsep media. Konsep media berisi tentang strategi komunikasi, gaya bahasa, pemilihan judul dan sinopsis yang akan disampaikan kepada target audience. Sedangkan konsep visual berisi tentang gaya ilustrasi, acuan warna, pemilihan layout dan pemilihan font tipografi. Dan yang terakhir adalah konsep media yang berisi tentang spesifikasi media utama yang digunakan, seperti ukuran buku, isi buku, jumlah halaman, dan harga penjualan, selain itu terdapat juga media pendukung yang berisi tentang strategi promosi yang akan digunakan.

\section{Produksi}

Produksi adalah tahap membuat media utama dalam perancangan, dan mengacu pada konsep desain yang sudah disusun di tahap pra produksi. Alternatif desain berguna untuk mengetahui desain terbaik dan cocok untuk target audience sebelum diterapkan dalam media utama. Pada tahap selanjutnya yaitu evaluasi desain, dilakukan untuk memilih desain yang sudah dibuat dari beberapa alternatif untuk kemudian dapat diperbaiki dan dikembangkan. Setelah desain alternatif terpilih, selanjutnya adalah melakukan eksekusi, yaitu proses menghasilkan hasil desain dari alternatif yang terpilih dan dikembangkan hingga menjadi desain yang sudah diimplementasikan dalam media utama dan siap untuk dipublikasikan kepada target audience.

\section{Pasca Produksi}

Tahap pasca produksi berguna untuk membuat kesimpulan tentang kekurangan dan kelebihan yang ada pada perancangan media utama, sehingga dari evaluasi dapat menjadi acuan perancangan berikutnya agar lebih baik lagi.

\section{HASIL DAN PEMBAHASAN}

\section{Tahap Persiapan}

\section{Hasil Pengumpulan Data}

Setelah dilakukan observasi diperoleh data bahwa anak-anak masih tidak terlalu paham dengan kesenian Jaranan Kediri, hanya sekedar mengetahui jaranan dari luarnya saja, tidak paham dengan bagaimana pentas jaranan berlangsung dari awal sampai akhir. Observasi juga dilakukan di beberapa toko buku yang ada di Surabaya yaitu di Togamas dan Gramedia. Data yang diperoleh dari hasil observasi tersebut diperoleh bahwa buku yang membahas tentang kesenian Jaranan masih kurang, sehingga sumber informasi yang didapat juga masih kurang dan susah untuk didapatkan.

Hasil wawancara yang sudah dilakukan kepada bapak Sutikno selaku pemilik sanggar Jaranan Sentono Putro diperoleh data bahwa kesenian Jaranan membutuhkan regenerasi pemain. Para pemain jaranan rata-rata pensiun saat mereka sudah menikah dan punya anak, sehingga dibutuhkan calon pemain jaranan yang bisa meneruskan kesenian Jaranan dan melestarikannya. Media informasi tentang jaranan yang dibutuhkan anak juga masih kurang.

\section{Hasil Analisis Data}

Data yang diperoleh kemudian dianalisis menggunakan teknik $5 \mathrm{~W}+1 \mathrm{H}$ (What, Where, 
Who, When Why, How), dan diperoleh data sebagai berikut:

a. What, apa permasalahan yang terjadi, dalam sebuah penelitian yang dilakukan, yaitu berdasarkan data observasi secara langsung anak usia 7 - 11 tahun masih banyak yang kurang tahu akan kesenian Jaranan Kediri, dan kurang tertariknya anak-anak terhadap kesenian lokal khas Kediri ini, dan tidak adanya media yang dapat menarik perhatian anak untuk dapat mengenal kesenian Jaranan Kediri.

b. Where, di mana masalah ini terjadi, masalah ini terjadi di wilayah daerah Kota Kediri dan sekitarnya

c. When, kapan masalah ini terjadi, masalah ini terjadi pada saat era digital, yang membuat kesenian tradisional seperti Jaranan Kediri mulai tergeser oleh budaya barat dan teknologi digital.

d. Who, siapa target audience yang dituju dalam perancangan ini, Anak usia 7 - 11 tahun yang tinggal di daerah kota Kediri dan sekitarnya merupakan target audiens dari perancangan ini.

e. Why, kenapa menggunakan buku ilustrasi sebagai media informasi. Buku ilustrasi merupakan buku yang dapat mencakup target audience yaitu anak usia 7 - 11 tahun, selain itu buku ilustrasi tidak memerlukan banyak kalimat dan gambar yang lebih mendominasi, karena anak - anak lebih tertarik dengan gambar yang muncul daripada tulisan.

f. How, bagaimana merancang buku ilustrasi. Perancangan buku ilustrasi ini dirancang dengan berbagai materi-materi yang dipelajari dari buku-buku yang sudah terbit tentang kesenian kuda lumping, dan disusun dengan ilustrasi yang cocok untuk anak dan cenderung menonjolkan gambar ilustrasi daripada kalimatnya.

Kesimpulan yang didapat dari analisa ditemukan bahwa buku ilustrasi kesenian jaranan Kediri sebagai media untuk informasi dan belajar anak, agar anak mengetahui dan memahami apa yang ada didalam kesenian jaranan Kediri, tidak hanya paham dari luarnya saja.

\section{Sintesis}

Berdasarkan analisis yang sudah dilakukan, diperolah sebuah sintesis data bahwa media informasi tentang jaranan Kediri sangat dibutuhkan untuk anak-anak, tetapi media yang disediakan untuk mempelajari kesenian Jaranan ini masih sedikit, akibatnya anak jadi tidak tahu apa itu jaranan Kediri. Oleh karena itu perancangan buku ilustrasi ini menjadi salah satu media informasi yang berisi tentang Jaranan Kediri yang menggunakan bahasa mudah dipahami dan lebih menonjolkan gambar ilustrasi daripada tulisan kalimat. Ukuran buku dikemas dengan ukuran 20 x 25 $\mathrm{cm}$ (portarit), agar visual yang ditampilkan jelas, selain itu dapat disimpan di tas anak, untuk kemudian bisa dibawa saat ke sekolah.

\section{Objek Perancangan}

Objek perancangan ini menggunakan media buku ilustrasi sebagai media utamanya. Materi yang ada didalam buku ini berisi pengertian kesenian jaranan secara umum, sejarah jaranan, alat musik yang digunakan saat jaranan pentas, menjelaskan beberapa lakon yang ada di dalam jaranan, terakhir tentang bagaimana tahap-tahap pentas jaranan dilakukan dari awal sampai akhir. Buku ini dikemas dengan bahasa yang sederhana dan 
mudah dipahami oleh anak, dan lebih menonjolkan visualnya dari pada tulisan kalimat.

\section{Tahap Penciptaan}

\section{Konsep Desain}

Konsep desain adalah tahapan selanjutnya setelah sintesa. Dalam konsep desain keyword mulai dapat ditemukan dengan menggunakan beberapa data yang telah dikumpulkan. Keyword dapat ditentukan dari beberapa poin yaitu, permasalahan, batasan masalah, tujuan perancangan, target audience, dan positioning. Dari beberapa poin tersebut dijabarkan kembali dan dijadikan dalam beberapa bentuk kata seperti dari poin permasalahan didapat kata mempelajari, dalam poin batasan masalah diperoleh kata kesenian Jaranan, tujuan perancangan didapat kata cinta, menjaga dan melestarikan, target audience didapat kata pemberani dan aktif, positioning didapat kata menyenangkan dan sederhana. Dari beberapa kata yang sudah didapatkan tadi dirangkum dalam satu kalimat keyword yaitu "Nyalakan Semangat Seni Jaranan, yang memiliki arti dalam Bahasa Indonesia yaitu keaktifan dalam menjaga dan melestarikan kesenian Jaranan Kediri dengan semangat dan tetap mempertahankan kesenian Jaranan, untuk kemudian diteruskan dari generasi ke generasi. Anak usia 7-11 tahun memiliki rasa penasaran yang tinggi, sehingga dengan media buku ilustrasi ini anak diharapkan mampu mempelajari atau mengenal kesenian Jaranan Kediri dengan mudah dan tanpa paksaan.

\section{Konsep Verbal}

Strategi komunikasi dari konsep verbal dalam perancangan buku ilustrasi kesenian Jaranan Kediri terletak pada pemilihan gaya bahasa yang sederhana, ringan, mudah dipahami oleh anak usia 7-11 tahun. Tipografi yang digunakan dalam buku ilustrasi juga tidak kaku, dan lebih menyesuaikan style untuk anak, mempunyai tingkat readibility dan legibility yang tinggi, sehingga mudah dipahami anak.

\section{Konsep Visual}

Dalam konsep visual yang disajikan akan mengambil beberapa visual yang terdapat pada Jaranan Kediri, seperti warna dan style gambar yang digunakan. Dalam Jaranan Kediri sendiri terdapat beberapa lakon di antaranya Jaranan, Barongan, Celengan, dan Pentulan.

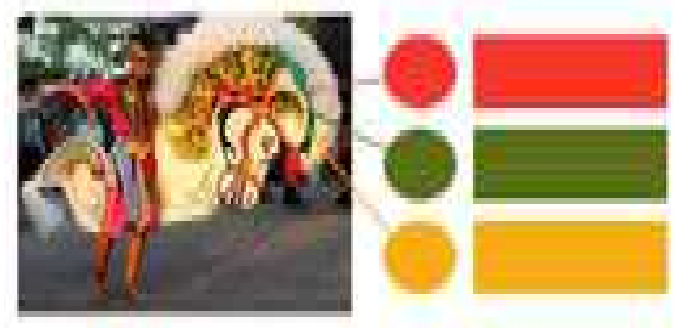

Gambar 2 Konsep Warna

Sumber: Youtube Moncos Channel, 2021
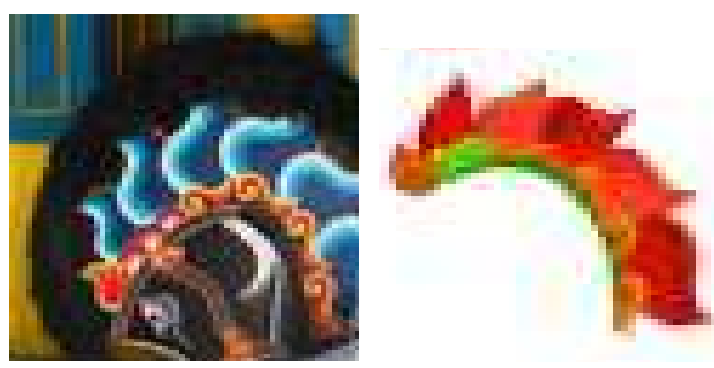

Gambar 3 Ilustrasi Supergrafis Sumber: Kompas.com, 2021

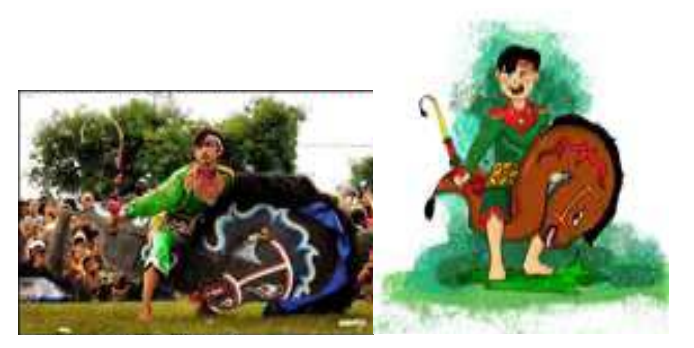

Gambar 4 Konsep Style Ilustrasi Sumber: Facebook Putri Kediri, 2021 


\section{HASIL AKHIR (FINAL DESAIN)}

Tahap akhir dalam perancangan desain, berupa rancangan visual buku yang sudah final, terdiri dari beberapa komponen visual cover buku, dan isi dari buku yang dirancang.

\section{a. Desain Cover Buku}

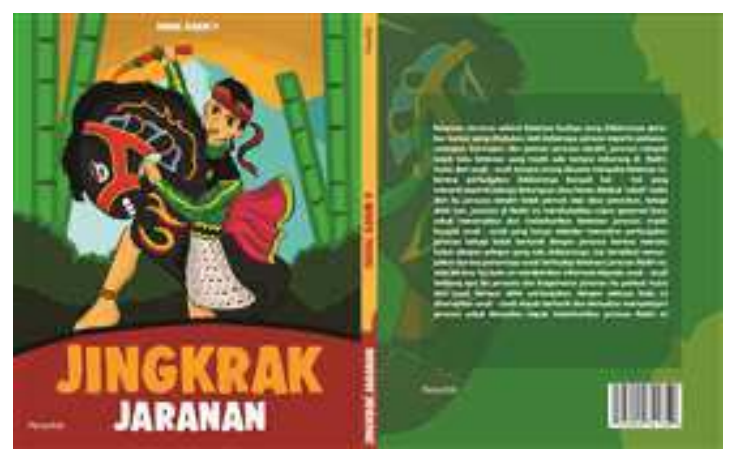

Gambar 5 Desain Cover Buku Sumber: Faisal Ilham Perdana, 2021

Cover buku menggambarkan seorang pemain Jaranan yang sedang melakukan gerakan dengan penuh semangat, yang menggambarkan bahwa Jaranan merupakan kesenian yang penuh dengan semangat dalam pemainnya.

b. Desain Judul Buku

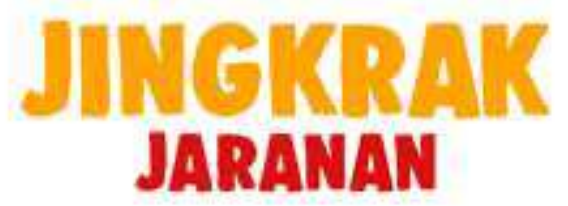

Gambar 6 Desain Judul Buku Sumber: Faisal Ilham Perdana, 2021

Font yang digunakan dalam Judul Buku "Jingkrak Jaranan" menerapkan readibility dan legibility yang tinggi, bertujuan memudahkan anak dalam membaca judul buku, selain itu mempunyai bentuk font yang sederhana dan pewarnaan yang cerah.

\section{c. Isi Buku}

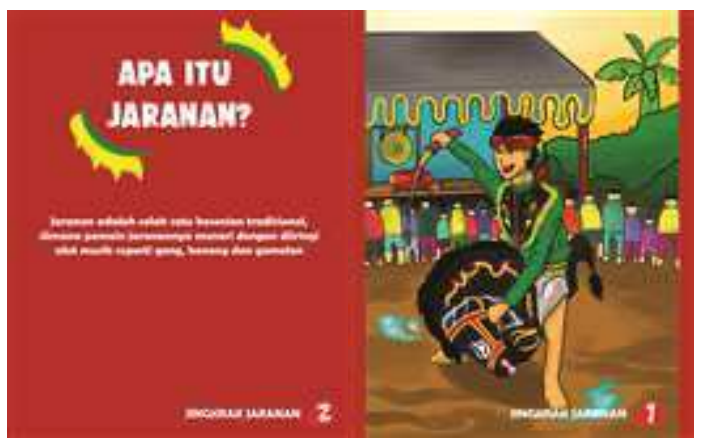

Gambar 7 Isi Buku Ilustrasi Sumber: Faisal Ilham Perdana, 2021

Isi buku ilustrasi terdiri dari gambar ilustrasi dalam satu halaman penuh dan di halaman lain merupakan deskripsi penjelasan dari ilustrasi yang terkait. Dalam deskripsi ilustrasi terdapat supergarfis yang merupakan salah satu elemen visual dari corak jaranan. Deskripsi isi buku dijelaskan secara sederhana dan ringkas agar mudah dipahami oleh anak.

\section{d. Desain Mockup Buku}

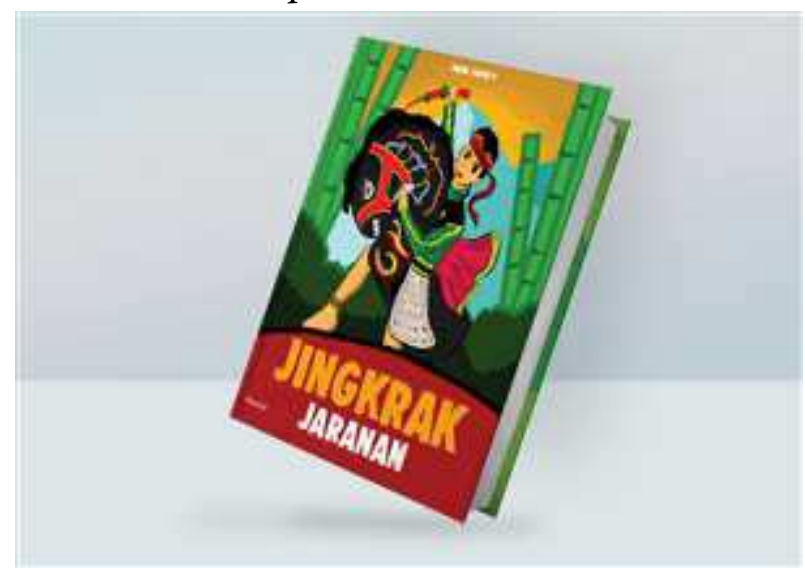

Gambar 8 Desain Mockup Buku Ilustrasi Sumber: Faisal Ilham Perdana, 2021

Desain ilustrasi diaplikasikan dalam mockup buku dengan ukuran buku $20 \times 25 \mathrm{~cm}$, yang 
bertujuan untuk memudahkan anak dalam membawa buku ilustrasi Jaranan. Bentuknya yang lebih kecil dari ukuran A4 juga bertujuan agar dapat dimasukkan ke dalam tas sekolah anak.

\section{KESIMPULAN}

Buku Ilustrasi adalah buku yang menyediakan informasi kepada audiens untuk menambah wawasan dan memberikan gambaran kesenian Jaranan Kediri yang sudah disampaikan dalam buku tersebut. Dalam sebuah buku ilustrasi dapat berhasil apabila dapat dipahami dan dapat diterapkan dengan baik oleh audiens. Buku ilustrasi "Jingkrak Jaranan" ini bertujuan untuk memberikan wawasan terkait informasi kesenian Jaranan Kediri agar anak usia 7-11 dapat mempelajari apa itu Jaranan dan bagaimana jalannya pentas Jaranan dari awal sampai akhir.

Dalam konten yang dibahas pada perancangan ini adalah tentang pengenalan dasar Jaranan seperti, alat musik Jaranan, lakon-lakon yang ada dalam sebuah pentas Jaranan. Pada bab selanjutnya membahas tentang bagaimana tahapan-tahapan pentas dalam Jaranan dari awal sampai akhir pertunjukan. Dan di bab terakhir membahas tentang pesan moral dari kesenian Jaranan Kediri, mitos negatif yang beredar di masyarakat, bagaimana kesenian Jaranan yang sebenarnya, yang semuanya bertujuan agar anak-anak tidak salah persepsi terhadap kesenian Jaranan Kediri.

Harapan dengan diterbitkannya buku ilustrasi ini yakni generasi muda khususnya anak usia 7 - 11 tahun dapat menambah wawasan tentang jaranan Kediri, sehingga dapat meningkatkan upaya untuk pelestarian jaranan Kediri di masa depan.

\section{REFERENSI}

[1] detik health. 2020. Otak Lebih Suka Gambar dan Warna. Health.Detik.Com. https://health.detik.com/beritadetikhealth/d-1404800/otak-lebih-sukagambar-dan-warna

[2] Gunawan, I. 2013. Metode Penelitian Kualitatif.: Teori dan Praktik. PT. Bumi Aksara.

[3] Ibda, F. 2015. Perkembangan Kognitif: Teori Jean Piaget. Intelektualita, 3, 27-38. https://jurnal.ar-

raniry.ac.id/index.php/intel/article/view/1 97

[4] Narbuko, C., \& Achmadi, A. 2010. Metode Penelitian. Bumi Aksara.

[5] NegerikuIndonesia.com. 2015. Tari Jaranan Kesenian Tradisional dari Jawa Timur. NegerikuIndonesia.Com. http://www.negerikuindonesia.com/2015/ 08/tari-jaranan-kesenian-tradisionaldari.html

[6] Nugroho, A. 2021. Iptu Rudi Darmawan, KBO Satlantas Polres Kediri Gemar Main Jaranan. Radarkediri.Jawapos.Com. https://radarkediri.jawapos.com/read/202 1/03/08/245822/iptu-rudi-darmawankbo-satlantas-polres-kediri-gemar-mainjaranan

[7] Pradana, A. P., \& Masnuna. 2021. Ilustrasi Buku Ensiklopedia Burung Rangkong. Andharupa, $\quad 7, \quad 28-43$. http://publikasi.dinus.ac.id/index.php/an dharupa/article/view/3537/2200

[8] Prakasa, A. A., Bahruddin, M., \& Yurisma, D. Y. 2016. Perancangan Buku Ilustrasi Jaranan Dengan Teknik Vektor Sebagai Upaya Melestarikan Budaya Lokal Kediri. Art Nouveau, 5, 216-224.

[9] Pramitasari, L. D. 2020. Determinan Kejadian Unmet Need pada Pasangan Usia Subur. [Poltekkes Kemenkes Yogyakarta].

http://eprints.poltekkesjogja.ac.id/3907/ 
[10] Putra, A. N., \& Lakoro, R. 2012. Perancangan Buku Ilustrasi Sejarah Musik Keroncong. Teknik Pomits, 1, 1-6.

[11] Winarsih, S. 2010. Mengenal Kesenian Nasional 12 Kuda Lumping. PT Bengawan Ilmu. 